\title{
A INSERÇÃO/REINSERÇÃO DA CRIANÇA COM DOENÇA RENAL CRÔNICA NA ESCOLA: A IMPLENTAÇÃO DE UM PROJETO DE DIALOGOS ENTRE ESCOLA E SERVIÇO DE SAÚDE
}

\author{
LA INSERCIÓN / REINSERACIÓN DEL NIÑO CON ENFERENCIA RENAL \\ CRÓNICA EN LA ESCUELA: LA IMPLANTACIÓN DE UN PROYECTO DE \\ DIALOGOS ENTRE ESCUELA Y SERVICIO DE SALUD
}

\begin{abstract}
THE INSERTION / REINSERTION OF CHILDREN WITH CHRONIC KIDNEY DISEASE (CKD) IN SCHOOLS: THE IMPLEMENTATION OF A DIALOGICAL PROJECT BETWEEN SCHOOL AND HEALTH SERVICE
\end{abstract}

Jodi Dee Hunt Ferreira do AMARAL ${ }^{1}$ Pérsia Karine Rodrigues Kabata FERREIRA ${ }^{2}$ Sônia Regina Fiorim ENUMO ${ }^{3}$

RESUMO: Este trabalho teve como objetivo a inserção/reinserção das crianças e adolescentes com Doença Renal Crônica (DRC) na escola uma vez constatado, pelo serviço psicopedagógico, que as mesmas não estavam frequentando as instituições regulares de ensino. Para tanto, foram realizadas visitas técnicas às escolas visando compreender a situação global da criança no meio escolar bem como instrumentalizar a equipe escolar com as informações necessárias sobre a DRC e seus consequentes cuidados nutricionais, emocionais e sociais. As visitas às escolas das crianças promoveram entrevistas e diálogos com toda a equipe escolar sendo possível observar e ouvir discursos dos profissionais envolvidos diretamente com a criança nos quais, os mesmos, consideravam-se "despreparados" e "mal informados" sobre a doença. Este estudo ressalta a importância da parceria eficaz das equipes: hospitalar e escolar quanto à manutenção da escolaridade do paciente com DRC. Ainda, para futuras ações, visa-se à sistematização da intervenção psicoeducativa.

PALAVRAS-CHAVES: Educação. Saúde. Hemodiálise. Psicoeducação. Intervenção.

RESUMEN: Este trabajo tuvo como objetivo la inserción/reinserción de los niños y adolescentes con Enfermedad Renal Crónica (DRC) en la escuela una vez constatado, por el servicio psicopedagógico, que las mismas no estaban frecuentando las instituciones regulares de enseñanza. Para ello, se realizaron visitas técnicas a las escuelas para comprender la situación global del niño en el medio de la escuela, así como instrumentalizar al equipo escolar con las informaciones necesarias sobre la DRC y sus

\footnotetext{
${ }^{1}$ Pontifícia Universidade Católica de Campinas (PUC-Campinas), Campinas - SP - Brasil. Doutoranda em Psicologia. E-mail: jdhfda@yahoo.com.br.

${ }^{2}$ Universidade Federal de Uberlândia (UFU), Uberlândia - MG - Brasil. Mestre em Educação. E-mail: persiakarine@ netsite.com.br

${ }^{3}$ Pontifícia Universidade Católica de Campinas (PUC-Campinas), Campinas - SP - Brasil. Professora orientadora do Programa de Pós-Graduação em Psicologia e do Mestrado em Ciências da Saúde (2015) da PUCCAMP. E-mail: sonia.enumo@gmail.com
} 
consecuentes cuidados nutricionales, emocionales y sociales. Las visitas a las escuelas de los niños promovieron entrevistas y diálogos con todo el equipo escolar siendo posible observar y oír discursos de los profesionales involucrados directamente con el niño en los que, los mismos, consideraban si "ningún preparo" y "mal informados" sobre la enfermedad. Este estudio resalta la importancia de la asociación eficaz de los equipos: hospitalario y escolar, en cuanto al mantenimiento de la escolaridad del paciente con DRC. Aún, para futuras acciones, se pretende la sistematización de la intervención psicoeducativa.

PALABRAS CLAVES: Educación. Salud. Hemodiálisis. Psicoeducación. Intervención.

ABSTRACT: The aim of this study was to integrate children and adolescents with Chronic Kidney Disease (CKD) in schools as it was verified, by the psychopedagogical service, that these children were not frequently attending regular educational institutions. Therefore, technical visits were made to schools aiming a global comprehension of the child in the school environment as well as offering the schools information about CKD and its consequent nutritional, emotional and social care. Visits to children's and adolescent's schools yielded interviews and dialogues with all school staff involved. This study highlights the importance of effective partnership between hospital and school teams regarding the maintaining the schooling of CKD patients. For future actions, systematization of psychoeducational intervention is to be sought.

KEYWORDS: Education. Health. Hemodialysis. Psychoeducation. Intervention.

\section{Introdução}

O presente artigo busca explanar algumas questões referentes à criança com Doença Renal Crônica (DRC) no Setor de Hemodiálise do Hospital de Clinicas da Universidade Federal de Uberlândia (HCU-UFU). O trabalho teve como objetivo a inserção ou reinserção das crianças e adolescentes com DRC na escola, uma vez que as mesmas não estavam frequentando as instituições regulares de ensino ou tinham alguma dificuldade de inserção nas mesmas. Foram realizadas visitas técnicas às escolas das referidas crianças para discutir e analisar o estado atual clínico, pedagógico e emocional das crianças, assim como para instrumentalizar a equipe escolar com as informações necessárias sobre a DRC e seus consequentes cuidados nutricionais, emocionais e sociais.

A DRC é a perda lenta, progressiva e irreversível das funções renais. Com isso, faz-se necessário a realização de terapia renal substitutiva, a qual vai "substituir" parcialmente as funções dos rins, e prevenir a ocorrência de lesão em outros órgãos (CHALLINOR, 2008). 
Entre os métodos de terapia renal substitutiva temos a hemodiálise, que é um processo que tem como objetivo principal, extrair substâncias tóxicas do sangue e remover o excesso de água. Este procedimento consiste na retirada do sangue do paciente de maneira contínua, através de um filtro, que após a retirada das substâncias tóxicas, o sangue então dialisado retorna ao paciente (ALMODÓVAR et al, 2007).

As crianças em programa ambulatorial de hemodiálise, têm em comum o fato de terem limitações para exercer suas atividades diárias, pois tornam-se dependentes do serviço hospitalar. Três vezes por semana passa, em torno de três a quatro horas/dia, em instituição para realização da hemodiálise. A dependência de ambiente hospitalar, o uso do cateter para hemodiálise, as internações frequentes, os procedimentos cirúrgicos são situações que o/a paciente e sua família precisam enfrentar.

Assim, observam-se prejuízos advindos da doença e do tratamento de pacientes, que alteram significativamente sua rotina, com a possibilidade de interferências no seu desenvolvimento psicológico, cognitivo, afetivo e social, como já visto por Compas et al. (2001).

Estudos sobre o desenvolvimento humano (FONSECA, 2003; ORTIZ e FREITAS, 2005; MATOS, 2009) revelam que a criança e o adolescente necessitam não só de cuidados básicos de alimentação, saúde e higiene, mas também de atenção, afeto, sexualidade, amizade e escolaridade, aspectos transformadores que influenciam sua autoestima e sua autoimagem. CECCIM e CARVALHO (1997, p. 31), acreditam que "para todas as crianças e adolescentes em nossa sociedade, a escola é um espaço social de vida. A manutenção desse espaço é uma necessidade para a criança e o adolescente".

Sendo a aprendizagem um processo não exclusivo da instituição escolar, por ocorrer inclusive em espaços não-escolares, ela pode acontecer com determinadas especificidades. No Setor de Hemodiálise, se faz presente o serviço psicopedagógico, em que se promove a construção do processo de leitura e escrita (alfabetização) com esses pacientes durante as sessões de diálise. Sabe-se que o sentido das aprendizagens é único e particular na vida de cada uma dessas crianças e que inúmeros são os fatores afetivoemocionais que podem impedir a aprendizagem. O serviço psicopedagógico, ao tratar as questões da aprendizagem, considera as dificuldades do sujeito com o meio e as dificuldades do meio com o sujeito, visto que essas duas dimensões devem ser analisadas reciprocamente. Ao compreender e elucidar os problemas e as dificuldades de aprendizagem busca agir operacionalmente, aproximando-se e buscando soluções pedagógicas a partir de uma leitura afetivo-cognitiva e social do problema. 
O espaço da pediatria, dentro do Setor de Hemodiálise, é por excelência, um ambiente carregado de emoções, tendo em vista que ao apresentar suas demandas, a criança sensibiliza tanto a equipe interdisciplinar como a família.

Baseando-se numa visão de desenvolvimento em que o sujeito é interativo e constrói o pensamento e o modo de ação num ambiente que é histórico e social, a atuação psicopedagógica visa ampliar as possibilidades de acesso desses pacientes a instrumentos físicos e simbólicos que possam constituir seus pensamentos, raciocínios e afetos.

Dados levantados pelo serviço psicopedagógico do Setor de Hemodiálise revelaram que essas crianças, antes de serem atendidas pelo referido serviço, se encontravam fora da escola regular de ensino. Os dados colhidos através de entrevistas (anamneses) realizadas com a família, sobre o motivo de essas crianças estarem fora da escola regular de ensino, apontam: 1) internações recorrentes; 2) dificuldades e limitações com o tratamento; 3) não aceitação da escola; 4) dificuldades no manejo com a doença e 5) dificuldades peculiares de cada criança.

De fato, Abreu et. al $(2014,2015)$ apontaram a questão da evasão escolar em crianças e adolescentes em Hemodiálise. Viera (2009) também revelou esta problemática da criança não frequentar a escola por medo de se machucar devido o uso do cateter ou de não frequentar a mesma, devido às idas ao hospital. Silva e Silva (2011) também apontam as dificuldades que o adolescente encontra no estudo e na convivência social.

Para Andrade (2009), a falta de convivência escolar é tão dolorosa quanto a falta de convivência familiar. Em ambiência hospitalar, a rotina da criança será diferenciada, mas não poderá deixar de existir. No entanto, a criança necessita ter hora para brincar, dormir, alimentar-se, realizar sua higiene pessoal, tomar suas medicações, realizar exames médicos, descansar e estudar.

Para tanto, pensar a interdisciplinaridade no ambiente hospitalar é fundamental para um processo e uma filosofia de trabalho que entra em ação na hora de enfrentar os problemas e questões que preocupam o contexto hospitalar. A inter-relação e interação dos saberes busca um objetivo comum, onde os métodos e estruturas de cada especialidade são ampliados e explorados com mais potencialidade, e configura-se, portanto, como uma ação que "busca o bem estar do paciente enfermo, preconizando a saúde como afirmação da vida e não somente como ausência da doença" (FERREIRA, 2011, p.114).

Busca-se assim olhar para essas crianças como um sujeito biopsicossocial, conforme preconiza a Organização Mundial de Saúde (OMS, 1946), na definição 
científica do conceito de saúde "estado de completo bem-estar físico, psíquico e social e não meramente a ausência de doença ou enfermidade". O tratamento, nessa perspectiva, pode ser entendido e visto pelas crianças com DRC como um convite a novas descobertas e aprendizagens.

Outro aspecto relevante que se pôde constatar a partir deste trabalho em equipe foi a necessidade de inserir ou reinserir as crianças na escola regular de ensino. Surgiram duvidas e foram levantadas algumas questões: Como assegurar-se de que uma informação adequada é suficiente para que professores e outros profissionais da escola possam atuar junto à essas crianças? O que as famílias esperam das crianças e como a escola pode ajudar em relação a essas expectativas? Como os sistemas escolares podem responder mais efetivamente a estas necessidades? Estas crianças deverão receber educação especial? Como adaptar procedimentos para atender às diferentes necessidades educacionais?

\section{Metodologia}

O Setor de Hemodiálise do HC-UFU situa-se no piso térreo do Bloco $2 \mathrm{P}$ do HCU/UFU, com data de inauguração em 29/11/2002. Iniciou suas atividades atendendo clientes do Sistema Único de Saúde (SUS) com doença renal terminal. Naquela época, oferecia a hemodiálise e a diálise peritoneal como modalidades de terapia renal substitutiva. Posteriormente, a diálise peritoneal deixou de ser oferecida como opção dialítica e os clientes com indicação para este tratamento passaram a ser referenciados a outro serviço credenciado.

Os clientes assistidos pelo serviço são provenientes do município de UberlândiaMG e demais cidades mineiras pactuadas: Coromandel, Monte Alegre, Monte Carmelo, Romaria, Prata, Estrela do Sul e Nova Ponte. Os clientes fazem sessões de hemodiálise três vezes por semana com duração de três a quatro horas cada sessão.

O Setor de Hemodiálise possui capacidade para atender 56 pacientes adultos e oito crianças. No momento que foi realizado este trabalho, contava com 42 pacientes adultos e 4 crianças, sendo o único serviço de referência em Uberlândia e região para o atendimento de crianças dependentes de hemodiálise. Fisicamente a unidade de hemodiálise do HC-UFU é dividida em três salões para atendimento de crianças, adultos sorologia negativa e adultos sorologia positiva para vírus Hepatite B. 
As quatro crianças que serão identificadas por nomes fictícios: Jennifer ( $\mathrm{J}$ ) é do sexo feminino com 9 anos de idade, Marcos (M) é do sexo masculino com 9 anos de idade, Valentina (V) é do sexo feminino com 8 anos de idade e Mauricio Leonardo (ML) é do sexo masculino com 9 anos de idade. Também foi realizada visita à escola de Diana (D), adolescente de 14 anos.

A relação entre Saúde e Educação é muito próxima. Ela circunda e constitui os processos de desenvolvimento, conhecimento e aprendizagem. Para tanto, discutiu-se na equipe multiprofissional a possibilidade de realizar visita técnica na escola desses pacientes.

Decidiu-se que o melhor caminho seria a visita técnica na escola das crianças objetivando instrumentalizar a equipe escolar para a inserção social desses pacientes.

A visita nas escolas dos(as) pacientes tinha por objetivo propiciar o entendimento e uma clara visão da doença e dos procedimentos terapêuticos à equipe escolar; como também problematizar a situação e os cuidados necessários com a criança renal crônica e identificar as possíveis dificuldades que professores, que atuam em sala com criança que apresenta DRC, têm.

Para a inserção das crianças na escola foram desenvolvidos os seguintes passos: 1) Consulta junto às famílias sobre qual escola iriam matricular as crianças, tendo em vista alguns aspectos como: localização; experiência dos pais com outros filhos nesta escola; concepções dos mesmos sobre a escola; expectativas; 2) Matrícula na escola (pais ou responsáveis); 3) Contato com a escola pelo serviço psicopedagógico do Setor de Hemodiálise; 4) Orientações às famílias sobre o desenvolvimento cognitivo e intelectual de cada criança para a inserção na escola; 5) Reunião entre a equipe interdisciplinar (médico, enfermagem, nutrição, psicologia e psicopedagogia) e família para orientações e encaminhamentos necessários; 6) Visita técnica à escola pela equipe multiprofissional através da liberação de transporte hospitalar pela diretoria do HC-UFU; 7) Visita da equipe escolar ao Setor de Hemodiálise e 8) Visita anual às escolas, a fim de reforçar os cuidados e orientações, além de promover a manutenção do contato entre equipe escolar e equipe interdisciplinar do serviço de hemodiálise, considerando as mudanças de turma e professores que ocorrem na vida escolar da criança. 


\section{Resultados}

A seguir serão relatados sucintamente os principais desdobramentos das visitas a cada escola.

A criança J, foi alfabetizada no serviço psicopedagógico no Setor de Hemodiálise. $\mathrm{J}$ havia frequentado a escola, 10 dias naquele ano devido às internações recorrentes e tratamento. A escola de J localiza-se no próprio município do Setor de Hemodiálise. Marcou-se uma visita e foi realizado um diálogo com a diretora, pedagoga e professora do atendimento especializado e a equipe visitante: psicopedagoga, psicóloga e nutricionista. Percebeu-se uma preocupação desta equipe escolar em relação à equipe de hospital visitante reveladas pelas seguintes indagações: "Vocês vieram nos ensinar como lidar com a J?". "Ela vai morrer?”. Neste momento, foi destacada a importância da escuta e reafirmação dos objetivos da visita. Identificou-se também o quanto que as experiências pessoais em relação ao adoecimento de cada profissional influenciavam a forma de lidar com a criança. Isto foi verificado através do relato da diretora que revelou seu próprio adoecimento pelo câncer, demonstrando muita angustia e medo ao lidar com a J. Este achado corrobora com o estudo de Nucci (2002), que encontrou dados semelhantes em suas pesquisas em escola com crianças com leucemia. Prosseguiu-se com as informações da nutricionista sobre cuidados nutricionais e de sua segurança quanto o cateter da criança pela nutricionista. Em seguida, verificou-se, no recreio a afetividade das outras crianças da escola em relação à $\mathrm{J}$. Foi observado que $\mathrm{J}$ estava rodeada de crianças em momentos descontraídos durante o recreio. Havia entusiasmo e brilho no olhar de J.

A criança $V$ foi alfabetizada no serviço psicopedagógico no Setor de Hemodiálise e encontrava-se frequente na escola regular, porém, após a avaliação psicopedagógica identificou-se inadaptação à metodologia proposta pela escola. No dia da visita, a equipe (psicopedagoga, nutricionista, psicóloga e enfermeira) foi recebida com interesse e entusiasmo pela equipe escolar (diretora, vice-diretora e professora). A escola localiza-se numa cidade do Triangulo Mineiro. Conversou-se sobre o tratamento de V, esclarecendo duvidas da equipe escolar quanto à realização da própria hemodiálise e questões referentes ao seu tratamento. Foram elucidados cuidados nutricionais, informações sobre o histórico familiar da V (incluindo as limitações familiares, pois a criança estava sob a guarda da avó paterna, devido a prisão do padrasto e o abandono pela mãe, usuária de drogas e o pai biológico ter construído outra família, morando na zona rural, a uma certa distância da filha) e o atendimento psicopedagógico e psicológico da mesma. Foi 
ressaltado o trabalho interdisciplinar realizado durante a sessão de hemodiálise pelo projeto "Fala Maria", que visa a contemplar os aspectos do cuidar, nutricionais, psicopedagógicos e psicológicos na adesão do tratamento e desenvolvimento das potencialidades das crianças frente à doença. Foi possível também dialogar sobre as necessidades pedagógicas detectadas da criança no hospital e os problemas de aprendizagem encontrados no processo de leitura e escrita.

A criança M. estuda em escola localizada numa cidade pequena no Triangulo Mineiro, cerca de $165 \mathrm{~km}$ do Hospital. A equipe escolar (diretora, vice-diretora, professora do ensino regular, professora do atendimento especializado, professor de apoio, supervisora, secretária) aguardava a equipe hospitalar (psicopedagoga, nutricionista, psicóloga e enfermeira), com muita expectativa de auxilio, no sentido de garantir um professor de apoio exclusivo uma vez que $\mathrm{M}$ era uma criança que apresentava um retardo mental de quatro anos e necessitava de ajuda quanto as suas necessidades básicas (uso de sanitário). É valido ressaltar que esta escola havia recusada a matricula do $\mathrm{M}$ anteriormente. Antes de $\mathrm{M}$ ingressar nessa escola, frequentava a Associação de Pais e Amigos dos Excepcionais (APAE). Conversou-se sobre o tratamento de $\mathrm{M}$ e os cuidados necessários dentro e fora do ambiente hospitalar. A professora mostrou-se muito afetiva e relatou o acolhimento da sala em relação a M. A equipe escolar foi informada sobre o inicio de processo de alfabetização da criança no Hospital bem como a expectativa e a insegurança da mãe quanto ao filho frequentar uma escola regular. A escola por sua vez solicitou relatório médico para a obtenção de um professor de apoio, e que foi atendido logo após a visita.

Quanto à ML, é importante salientar que, além da doença crônica renal, era portador de baixa visão detectada no atendimento psicopedagógico. A escola de ML é localizada no Triangulo Mineiro, cerca de $152 \mathrm{~km}$ do Hospital. A criança frequentou a escola por apenas um ano, antes de descobrir a DRC. No atendimento psicopedagógico, foi identificado que a criança já estava alfabetizada, sem os conhecimentos dos pais, e segundo relato da criança, foi alfabetizado pela irmã.

A equipe escolar (diretora, supervisora e professora) recebeu a equipe hospitalar (psicopedagoga, nutricionista, psicóloga e enfermeira) para uma reunião que se pautou pelo tratamento, tanto, do DRC quanto da baixa visão, e os cuidados necessários, orientações sobre a necessidade de ampliação do material pedagógico, o uso do lápis e distância do quadro. 
Fez-se visita à sala da criança e a professora relatou que a criança interagia pouco com os colegas, apesar destas estarem receptivas ao contato. Percebeu-se que isto poderia ser extensiva à forma com que era tratada em casa. ML era "privilegiado" por ter um temperamento difícil, não compartilhando suas coisas e tendo seu próprio quarto e outras regalias (permissão de certos alimentos e sua quantidade aumentada) enquanto os outros quatro irmãos, de ambos os gêneros, ficavam todos num único quarto.

A criança D, estuda em escola localizada no Triangulo Mineiro, cerca de $111 \mathrm{~km}$ do Hospital. Além da conversa da equipe hospitalar (psicopedagoga, nutricionista, psicóloga e enfermeira) com a diretora da escola, foi feito contato com os colegas de D, na presença desta. Foi um momento interativo e os alunos fizeram várias perguntas, inclusive sobre se poderiam doar um rim à $\mathrm{D}$. Aproveitou-se este momento para divulgar e distribuir o livro que D havia escrito durante os atendimentos psicopedagógicos nas sessões de Hemodiálise. Percebeu-se a importância de D contar sua historia e autografar os livros.

\section{Considerações finais}

A intervenção interdisciplinar no Setor de Hemodiálise é um trabalho contínuo e cheio de descobertas. Não existem verdades e soluções prontas. Os caminhos e as possibilidades são construídos no decorrer dos atendimentos, à medida que o paciente se deixa conhecer. A atuação psicopedagógica e psicológica é fortemente marcada pelas relações afetivas.

Os questionamentos quanto à vivencia escolar de uma criança com doença renal crônica levam a reflexões sobre intervenções e planejamentos que exigem a colaboração de toda a equipe multiprofissional para a efetivação de ações.

Os dados colhidos pelo serviço psicopedagógico através de entrevistas (anamneses) junto às famílias, revelaram as dificuldades e limitações das mesmas para inserir as crianças na escola, tais como: internações recorrentes; dificuldades e limitações com o tratamento; não aceitação da escola e dificuldades peculiares de cada criança.

Inserir as crianças na escola era uma necessidade detectada pelo serviço psicopedagógico, assim como por toda a equipe. Então, após discussão em equipe, levantaram-se dúvidas e questionamentos: Como assegurar-se de que uma informação adequada é suficiente para que professores e outros profissionais da escola possam atuar 
junto à essas crianças? O que as famílias esperam das crianças e como a escola pode ajudar em relação a essas expectativas? Como os sistemas escolares podem responder mais efetivamente a estas necessidades? Essas crianças deverão receber educação especial? Como adaptar procedimentos para atender às diferentes necessidades educacionais? Para tanto, decidiu-se que a visita técnica de toda a equipe multiprofissional do setor de hemodiálise às escolas seria relevante para a criança, para a família e também para a escola.

As visitas às escolas das crianças oportunizaram entrevistas e diálogos com toda a equipe escolar. Foi possível observar no discurso, dos profissionais envolvidos diretamente com a criança (professores, pedagogos entre outros), que se consideram “despreparados" e "mal informados" sobre a doença, solicitando esclarecimentos sobre a mesma.

Reforça-se assim, a importância de se desenvolver ações que visem o estreitamento da relação entre educação e saúde. A escola representa um importante e considerável elemento no desenvolvimento infantil, ao lado da família e é a escola que trará a influência mais importante do ponto de vista psicossocial. A preocupação com o desenvolvimento e a aprendizagem da criança, encontra-se perfeitamente na interface entre a busca da recuperação da saúde e a preservação do direito à educação.

As crianças com Doença Renal Crônica, dentro do Setor de Hemodiálise, somente serão integralmente atendidas se, ao lado da preocupação e dos cuidados com o tratamento, houver a preservação das inter-relações familiares e sociais, procurando evitar o retraimento ou isolamento do(a) doente. Para tanto, faz-se necessário um trabalho eficaz em equipe, capaz de orientar, informar e apoiar o paciente e sua família, em questões práticas, entre as quais, a manutenção da escolaridade.

Para futuras intervenções, visa-se à sistematização de uma intervenção psicoeducativa. Nas salas de aula serão apresentadas informações sobre o DRC bem como atividades lúdicas para a retenção do conteúdo apresentado e material gráfico impresso para os alunos. Esta intervenção poderia ser estendida à comunidade escolar (equipe pedagógica e outros funcionários como também pais).

\section{REFERÊNCIAS}


ABREU, Isabella Schroeder et al. Children and adolescents on hemodialysis: attributes associated with quality of life. Rev. Esc. Enferm. USP, São Paulo, v. 48, n. 4, p. 602609, ago. 2014.

ABREU, Isabella Schroeder et al. Crianças e adolescentes com insuficiência renal em hemodiálise: percepção dos profissionais. Rev. Bras. Enferm., Brasília, v. 68, n. 6, p. 1020-1026, dec. 2015.

ANDRADE, J. C. Educação: um direito interrompido? In: Escolarização hospitalar: educação e saúde de mãos dadas para humanizar. Petrópolis/RJ: Vozes, 2009, p.118131.

ALMODÓVAR, A. A. B. et al. Detecção de bactérias Gram-negativas não fermentadoras em água tratada para diálise. Revista Instituto Adolfo Lutz, v.66, n. 2, p. 172-175, 2007.

CECCIM, R. B.; CARVALHO, P. R. A. (Org). Criança hospitalizada: atenção integral como escuta a vida. Porto Alegre: Editora da Universidade/UFRGS, 1997.

CHALLINOR, P. Hemodialysis In: CHALLINOR, P. Renal Nursing. Tindall Elsevier: Ed Thomas, p. 181-222, 2008.

COMPAS, B. C.; CONNOR-SMITH, J. K.; SALTZAMAN, H.; THOMSEN, A. H.; WAGSWORTH, M. E. Coping with stress during childhood and adolescence: Problems, progress, and potential in theory and research. Psychological Bulletin, 127(1), 87-127, 2001.

FERREIRA, P. K. R. K. O apoio psicopedagógico ao paciente em tratamento prolongado: uma investigação sobre o processo de aprendizagem no Hospital de Clínicas da Universidade Federal de Uberlândia. 2011. 122 f. Dissertação (Mestrado em Educação) - Faculdade de Educação, Universidade Federal de Uberlândia, Uberlândia, 2011.

FONSECA, E. S. Atendimento escolar no ambiente hospitalar. São Paulo: Memnon, 2003.

MATOS, L. M. (Org.). Escolarização hospitalar: educação e saúde de mãos dadas para humanizar. Petrópolis, RJ: Vozes, 2009.

NUCCI, N. A. G. A criança com leucemia na escola. Campinas/SP: Livro Pleno, 2002.

ORTIZ, L. C. M.; FREITAS, S. N. Classe hospitalar: caminhos pedagógicos entre saúde e educação. Santa Maria: Ed. UFSM, 2005.

ORGANIZAÇÃO MUNDIAL DE SAUDE (OMS). Preamble to the Constitution of the World Health Organization as adopted by the Internatioanal Health Conference. New York, 19-22 junho, 1946. 
SILVA, S. E. M.; SILVA, L. W. S. Impacto da hemodiálise na vida de adolescentes acometidos pela insuficiência renal crônica. Adolesc Saude. 2011;8(1):43-50.

VIEIRA, Sheila de Souza.; DUPAS, Giselle.; FERREIRA, Noeli Marchioro Liston Andrade. Doença renal crônica: conhecendo a experiência da criança. Esc. Anna Nery, Rio de Janeiro, v. 13, n. 1, p. 74-83, mar. 2009.

\section{Como referenciar este artigo}

AMARAL, Jodi Dee Hunt Ferreira do.; FERREIRA, Pérsia Karine Rodrigues Kabata.; ENUMO, Sônia Regina Fiorim. A inserção/reinserção da criança com doença renal crônica na escola: a implentação de um projeto de diálogos entre escola e serviço de saúde. Temas em Educ. e Saúde, Araraquara, v.13, n.2, p. 197-208, jul./dez. 2017. Disponível em: <https://doi.org/10.26673/rtes.v13.n2.jul-dez.2017.9601>. E-ISSN: 2526-3471.

Submetido em: 25/03/2017

Aprovado em: 20/06/2017 